\title{
Risk of spontaneous abortion in workers exposed to toluene
}

\author{
Tze Pin Ng, Swee Cheng Foo, Theresa Yoong
}

\begin{abstract}
Rates of spontaneous abortions were determined using a reproductive questionnaire administered by personal interview to 55 married women with 105 pregnancies. They were employed in an audio speaker factory and were exposed to high concentrations of toluene (mean 88, range 50-150 $\mathrm{ppm}$ ). These rates of spontaneous abortion were compared with those among 31 women (68 pregnancies) who worked in other departments in the same factory and had little or no exposure to toluene (0-25 ppm), as well as with a community control group of women who underwent routine antenatal and postnatal care at public maternal health clinics (190 women with 444 pregnancies). Significantly higher rates for spontaneous abortions were noted in the group with high exposure to toluene $(12.4$ per 100 pregnancies) compared with those in the internal control group (2.9 per 100 pregnancies) and in the external control group (4.5 per 100 pregnancies). Among the exposed women, significant differences were also noted in the rates of spontaneous abortion before employment (2.9 per 100 pregnancies) and after employment in the factory (12.6 per 100 pregnancies). Almost all the women were nonsmokers and did not drink; other known risk factors such as maternal age at pregnancy, order of gravidity, and race were not likely to explain the results. Thus, specific exposure to toluene seems to be associated with a risk of foetal loss.
\end{abstract}

(British Journal of Industrial Medicine 1992;49:804-808)

Several epidemiological studies have suggested increased risk of spontaneous abortion in association with exposure to organic solvents in various occupations, such as painting, dry cleaning, pharmaceutical

Department of Community, Occupational and Family Medicine, National University of Singapore T P Ng, S C Foo

Health Services for the Elderly, Ministry of Health, Singapore, Formerly Maternal and Child Health Services, Ministry of Health, Singapore

T Yoong manufacturing, and laboratory work, although negative results have also been reported. (A comprehensive recent review of published results can be found in an article by Taskinen. ${ }^{1}$ ) Most of these studies have, however, examined the risk of spontaneous abortion from exposures to organic solvents in general, and not to specific solvents. Toluene is a common solvent used either singly or in solvent mixtures in many industrial processes, and many women in the reproductive age group are exposed. Among the few such studies that have examined the embryotoxic effects of exposure to toluene one has found an increased risk of spontaneous abortion (not statistically significant) in pharmaceutical workers, ${ }^{2}$ and another an increased risk in shoemakers. ${ }^{3}$ Here we report the results of a study of the risk of spontaneous abortions in a group of women involved in the manufacture of audio speakers who were exposed only to toluene.

\section{Materials and methods}

The factory, environmental exposure to toluene, and the study populations have been described in detail previously. ${ }^{46}$ Briefly, the factory manufactured audio speakers, and exposed workers to high airborne concentrations of toluene (mean 88, range 50-150 $\mathrm{ppm}$ ) in final bond assembly processes that used large quantities of toluene with resinous glues. Other production workers were exposed to little or no toluene (range 0-25 ppm), in separate departments that made coil and cone speaker parts, although some of them were exposed to low levels (well below American Conference of Governmental Industrial Hygienists threshold limit values) of other hazards such as noise, heat, lead, methanol, and methyl ethyl ketones. A total of 343 women were employed in full time daily production work in these departments.

Of the 309 women successfully interviewed $(90 \%$ response rate) for the study, 106 were married, and a detailed reproductive history was taken of the 86 married women who had had at least one pregnancy. These included 55 women who were working in the final bond assembly departments, which exposed them to high concentrations of toluene, and 31 women in the coil and cone departments, where the exposure was low.

We also studied an external control group of women in the community who were receiving routine 
Table 1 Basic characteristics of subjects

\begin{tabular}{|c|c|c|c|}
\hline & $\begin{array}{l}\text { Maternal health } \\
\text { clinic women }\end{array}$ & $\begin{array}{l}\text { Low } \\
\text { exposure }\end{array}$ & $\begin{array}{l}\text { High } \\
\text { exposure }\end{array}$ \\
\hline No of subjects & 190 & 31 & 55 \\
\hline Age $(y)$ at interview (mean (SD)) & $28 \cdot 6(4 \cdot 2)$ & $35 \cdot 2(8 \cdot 5)$ & $30 \cdot 7(6 \cdot 2)$ \\
\hline Years employed in plant (mean (SD)) & - & $9 \cdot 7(4 \cdot 7)$ & $10 \cdot 0(4 \cdot 4)$ \\
\hline $\begin{array}{l}\text { Total No of pregnancies } \\
\text { Mean No of pregnancies per woman }\end{array}$ & $\begin{array}{r}444 \\
2 \cdot 3\end{array}$ & $\begin{array}{l}68 \\
2 \cdot 2\end{array}$ & 105 \\
\hline $\begin{array}{l}\text { No of live births } \\
\text { Mean No of live births per woman } \\
\text { Maternal age (y) at gestation (mean (SD)) }\end{array}$ & $\begin{array}{l}397 \\
2 \cdot 1 \\
26 \cdot 5(4 \cdot 4)\end{array}$ & $\begin{array}{l}66 \\
2 \cdot 1 \\
27 \cdot 2(4 \cdot 7)\end{array}$ & $\begin{array}{l}92 \\
1 \cdot 7 \\
26 \cdot 2(4 \cdot 6)\end{array}$ \\
\hline $\begin{array}{l}\text { Order of gravidity (No }(\%) \text { ) } \\
1 \\
2 \\
3 \\
4 \\
5 \\
6\end{array}$ & $\begin{array}{c}189(42 \cdot 5) \\
143(32 \cdot 1) \\
72(16 \cdot 2) \\
29(6 \cdot 5) \\
9(2 \cdot 0) \\
3(0 \cdot 7)\end{array}$ & $\begin{array}{c}34(50 \cdot 0) \\
18(26 \cdot 5) \\
10(14.7) \\
5(7.3) \\
1(1.5) \\
0(0.0)\end{array}$ & $\begin{array}{c}59(56.2) \\
29(27.6) \\
12(11.4) \\
4(3.8) \\
1(1.0) \\
0(0.0)\end{array}$ \\
\hline Alcohol regularly at least once a week $(\mathrm{No}(\%))$ & $0(0 \cdot 0)$ & $1(3 \cdot 2)$ & $0(0 \cdot 0)$ \\
\hline Past and current smokers (No (\%)) & $4(2 \cdot 1)$ & $2(6 \cdot 5)$ & $0(0 \cdot 0)$ \\
\hline
\end{tabular}

antenatal and postnatal care in public (government) maternal health clinics situated in several industrial areas, among which the factory was located. A total of 190 women were consecutively interviewed at the clinics, with no refusals. Among them, 29 women $(15 \%)$ were currently employed in factory production jobs, and 104 were currently housewives (55\%). Among the housewives, 66 were employed in factory production jobs in their last previous employment (35\% of total).

The interviews were conducted by two trained female field investigators who administered a structured questionnaire. The principal parts comprised questions related to: (1) occupational exposurenamely, date of first employment in the factory, department worked, job transfers if any within the factory, other previous exposure to solvents and other hazardous metals and chemicals, shift work, frequent heavy lifting, and carrying of loads on the job; (2) personal habits such as smoking and alcohol consumption; (3) medical and reproductive histories which included previous use of contraceptives, number of pregnancies confirmed by a doctor, date and outcome of each pregnancy, and relevant medical and drug histories and complications during pregnancy. Only abortions from curettage after diagnosis by a medical practitioner were determined, and spontaneous and induced abortions were clearly distinguished by probing questions as to the reasons for the curettage. Spontaneous abortion was defined by its occurrence after 12 weeks and before 28 weeks of pregnancy.

All women who were currently pregnant were reinterviewed at the expected time of completion of their pregnancy to ascertain their pregnancy outcomes.
Spontaneous abortion rate was defined as the number of spontaneous abortions divided by the number of pregnancies (including induced abortions). The statistical analyses used different pregnancies of the same women as units, assuming that these were statistically independent. Rates were compared using standard contingency tables with significance tests ( $\chi^{2}$ or Fisher's exact test) and multiple logistic regression analyses for controlling of known confounding risk factors.

\section{Results}

The 55 women in the hgh exposure group and the 31 women in the low exposure group contributed 68 and 105 pregnancies respectively (total 173 pregnancies) (tables 1 and 2). A total of 15 spontaneous abortions were noted; 13 in the high exposure and two in the low exposure groups. The 190 women from the maternal health clinics had 444 pregnancies, of which 20 ended in spontaneous abortions. Table 2 shows spontaneous abortion rates per 100 pregnancies in these groups. Significantly higher rates of spontaneous abortion were noted in the high toluene exposure group, compared with either control group.

Table 2 Spontaneous abortion rates by exposure

\begin{tabular}{llrlll}
\hline & \multirow{2}{*}{$\begin{array}{c}\text { No of } \\
\text { pregnancies }\end{array}$} & \multicolumn{4}{c}{ Spontaneous abortions } \\
\cline { 2 - 5 } & \multicolumn{1}{c}{ No } & Rate $(\%)$ & p Value \\
\hline High exposure & 105 & 13 & 12.4 & $\star$ \\
Low exposure & 68 & 2 & 2.9 & 0.025 \\
$\begin{array}{l}\text { Maternal health } \\
\text { clinic group }\end{array}$ & 444 & 20 & 4.5 & 0.005 \\
\hline
\end{tabular}

*High exposure compared with low exposure and maternal health clinic group respectively. 
We further analysed the risks of spontaneous abortion in relation to exposure in the toluene workers by defining unexposed and exposed pregnancies in the same women according to their occurrence before and after their employment in the factory (table 3). Significantly higher rates of spontaneous abortions were noted in exposed pregnancies (after employment) than in unexposed pregnancies (before employment) overall, although in the substrate of high and low exposure groups, the power to detect statistical significance was limited by small sample sizes.

An examination of the distribution of classical risk factors for spontaneous abortions among the various comparison groups suggested little likelihood of confounding of the observed association by the classical risk factors of maternal age at pregnancy and order of gravidity (table 1). The odds ratios of risk of spontaneous abortions associated with each of the exposure parameters was not significantly altered after adjustment for these risk factors (table 4). Few of the women smoked cigarettes or drank alcohol and race was not significantly associated with risk of spontaneous abortions.

Six women reported ever using intrauterine devices for contraception before their pregnancies (two in women with high exposure to toluene, four in the maternal health clinics group), but none of these women had spontaneous abortions.

Four women in the high toluene exposure group had repeated spontaneous abortions (one who aborted three times, three who aborted twice), and one woman in the maternal health clinics group aborted

Table 3 Spontaneous abortion rates for exposed and unexposed pregnancies

\begin{tabular}{lccc}
\hline & $\begin{array}{l}\text { No of } \\
\text { pregnancies }\end{array}$ & $\begin{array}{l}\text { No (\%) of } \\
\text { spontaneous } \\
\text { abortions }\end{array}$ & p Value \\
\hline $\begin{array}{l}\text { High exposure: } \\
\begin{array}{l}\text { Before employment } \\
\text { After employment }\end{array}\end{array}$ & 32 & $2(6 \cdot 2)$ & \\
$\begin{array}{l}\text { Low exposure: } \\
\text { Before employment }\end{array}$ & 33 & $11(15 \cdot 1)$ & 0.175 \\
$\begin{array}{l}\text { After employment } \\
\text { All exposure: } \\
\text { Before employment } \\
\text { After employment }\end{array}$ & 30 & $0(0.0)$ & \\
\hline
\end{tabular}

Table 4 Odds ratios (OR) of spontaneous abortions associated with exposure to toluene, adjusted for maternal age and gravidity

\begin{tabular}{lll}
\hline & $O R \quad(95 \%$ CI $)$ \\
\hline High exposure $v$ low exposure & 4.80 & $(1 \cdot 01-22 \cdot 86)$ \\
High exposure $v$ maternal health clinic & $2 \cdot 79$ & $(1 \cdot 32-5 \cdot 88)$ \\
women & 5.72 & $(1 \cdot 14-28 \cdot 75)$ \\
After employment $v$ before employment & \\
\hline
\end{tabular}

twice. As the risk of spontaneous abortion is also influenced by the occurrence of previous abortions, a high rate of repeated abortions might account to some extent for the higher rates of spontaneous abortion among the highly exposed women. One method of eliminating the influence of this factor is to restrict the analysis of the risks of spontaneous abortions to only first pregnancies. Because of small sample size, however, it was not feasible to analyse the data in this way. It was also not possible to control for previous abortions as a covariate in the multiple logistic regression for reasons discussed later.

\section{Discussion}

We have found that rate of spontaneous abortion is associated with exposure to toluene. There are few other studies of the relation between exposure to touene and spontaneous abortions with which our results could be directly compared. A case-control study of pharmaceutical workers showed a slight non-significant, increase in risk of spontaneous abortion associated with exposure to toluene. ${ }^{1}$ The degree of exposure to toluene was unknown and exposures to other solvents also occurred. Another case-control study showed significantly high risk of abortion associated with exposure to toluene in shoemakers (odds ratio $9 \cdot 3,95 \%$ confidence interval $(95 \% \mathrm{CI}$ ) $1 \cdot 0-84 \cdot 3){ }^{2}$ The shoemakers were exposed to concentrations of toluene ranging from $1 \mathrm{ppm}$ to $33 \mathrm{ppm}$, but they were also exposed to acetone and high concentrations of hexane (33-56 ppm). The only other study that examined an occupationally defined group of women with reasonably homogeneous exposure to toluene (mean $55 \mathrm{ppm}$, range 13-120 $\mathrm{ppm}$ in the production of electrical insulating materials) examined the outcome of pregnancy based on records of deliveries and newborn babies. ${ }^{7}$ Although similar rates of pregnancies and a higher rate of low birth weight babies were found compared with office controls, direct determinations of rates of spontaneous abortion were not done. Animal tests show that toluene is fetotoxic and causes a reduction in fetal weight, retarded ossification, and skeletal anomalies; at high air concentrations or after oral administration of non-toxic doses, it is embryolethal. ${ }^{8}$

It is interesting that higher rates of spontaneous abortions in the women with high exposure to toluene were consistently found in separate comparisons with two different groups of controls. The factory control group of women were essentially similar to the women with high exposure to toluene particularly for education and socioeconomic state, which reflects nutrition, adequacy of health care, and other associated risk factors; also neither group was employed in shiftwork or physically demanding tasks in the factory. The rates of spontaneous abortions in 
the factory control group was, however, based on small numbers, thus still allowing the possibility of the differences found being due to chance.

It is reassuring, therefore, to note similar rate differences in another group of controls. These were women attending community based maternal health services clinics that provided routine anticipatory care and monitoring of all pregnancies, including the screening and referral of complications during pregnancy. The women who used these primary health care services tended to have a lower socioeconomic background than the rest of the population, and many of them were currently, or had been, manufacturing production workers. In terms of socioeconomic factors, therefore, they were also comparable with the women exposed to toluene in the factory. At the same time it was considered that their data were likely to reflect the background rates of spontaneous abortions for this socioeconomic class of women in the community.

The rate differences between groups compared were not likely to be confounded by classical risk factors such as maternal age, gravidity, smoking, or alcohol, which were taken into account both in the study design and the analyses. A history of previous abortions is a known risk factor for spontaneous abortion, and a higher rate of repeat abortions could well account for the higher rates of spontaneous abortions in the women with high exposure to toluene. It could, however, also have resulted from exposure to toluene. In other words, rather than regarding it solely as a confounding risk factor for spontaneous abortion, repeated abortions may also be regarded as a response variable in relation to exposure to toluene. Because of this autorelation it was not feasible to include previous abortion simultaneously with exposure to toluene in the multiple logistic regression.

Response bias and reporting bias should be considered in interpreting the results. High participation rates were obtained for all groups, but in crosssectional studies of spontaneous abortions among working women, there is a possible selection bias in that women who have had successful pregnancies were more likely to stop working than women who have had spontaneous abortions'; the community controls might possibly have a lower rate of spontaneous abortions on this account. Nevertheless, the interpretation of the results is facilitated by comparing rates with the control group of women working in the same factory. All current pregnancies in these women were also followed up, with no observable differences in rates, although the numbers were few.

Unequivocal information was obtained on exposure to toluene in each group of women in the factory. This was seldom achieved in previous studies because most exposures studied (especially case-control studies) were heterogeneous, and specitic exposures rare. The present study employed an occupationally defined population with homogeneous exposure to toluene. Although the internal factory control group was exposed to low levels of other hazards as well, this is liable to bias the results if anything towards diminishing any differences between the groups compared.

Information on pregnancy outcomes might be biased by questionnaire interview. It was not possible in the present study to validate pregnancies and spontaneous abortions among the exposed women by access to medical records or with biological methods. Among the maternal health clinics group, $90 \%$ of the reported pregnancies and spontaneous abortions were verified in the medical records. To avoid differential bias in reporting of spontaneous abortions, the exposed workers were only told that the study was aimed at studying the health of working women in general and the relation to exposure to toluene was not mentioned. It may be assumed that the women with low exposure to toluene in the coil and cone sections would be equally biased in reporting spontaneous abortions if they believed that their work and exposure had anything to do with adverse pregnancy outcomes. Furthermore, to ensure maximum validity, relatively unequivocal endpoints were used in determining pregnancies and spontaneous abortions in the questionnaire, by excluding doubtful pregnancies or early spontaneous abortions that might be construed as delayed menstrual bleeding.

This may partly explain the comparatively low rates of spontaneous abortions found in the control groups in this study. Rates of spontaneous abortions in the general population vary from 5 to $10 \%$ when the event is ascertained retrospectively by means of a questionnaire. ${ }^{10}$ Given the potential for recall bias and under-reporting, the reference rates of spontaneous abortion found in the present study were therefore comparable.

In conclusion, the present study suggests a high risk of spontaneous abortions associated with specific exposure to toluene. Further studies are, however, required to confirm these findings, and to determine if these effects on reproductive outcomes are reversible at lower amounts of exposure.

We thank the management and workers of the factory and staff and patients at the maternal and child health services for their cooperation, and $\operatorname{Dr} M M$ Thein, Ms Ng Yuen Ling, and Mrs Julie Tan for their assistance in this study.

Requests for reprints to: $\mathrm{Dr} \mathrm{T} \mathrm{P} \mathrm{Ng}$, Department of Community, Occupational, and Family Medicine, National University of Singapore, Lower Kent Ridge, Singapore 0511. 
1 Taskinen HK. Effects of parental occupational exposures on spontaneous abortion and congenital malformation. Scand $J$ Work Environ Health 1990;16:297-314.

2 Lindbohm ML, Taskinen HK, Salimen M, Hemminki K. Spontaneous abortions among women exposed to organic solvents. Am J Ind Med 1990;17:449-63.

3 Taskinen HK, Lindbohm ML, Hemminki K (1986). Spontaneous abortions among women working in the pharmaceutical industry. Br J Ind Med 1986;43:199-205.

4 Foo SC, Phoon WO, Khoo NY. Toluene in blood after exposure to toluene. Am Ind Hyg Assoc J 1988;49:255-8.

5 Foo SC, Jeyaratnam J, Koh D. Chronic neurobehavioural effects of toluene. Br J Ind Med 1990;47:480-4

$6 \mathrm{Ng}$ TP, Foo SC, Yoong T. Menstrual function in workers exposed to toluene. $\mathrm{Br} J$ Ind Med 1992;49:799-803.

7 Syrovadko ON. Working conditions and the state of health of women working with organosilicon varnishes containing toluene. Gig $\operatorname{Tr}$ Prof Zabol 1977;12:15-9.

8 Barlow SM, Sullivan FM. Reproductive hazards of industrial chemicals. London: Academic Press 1982:538-49.

9 Axelsson G. Selection bias in studies of spontaneous abortions among occupational groups. J Occup Med 1984;26:525-8.

10 Hemminki K, Niemi ML, Saloniemi I, Vainio H, Hemminki E. Spontaneous abortions by occupational and social class in Finland. Int J Epidemiol 1980;9:149-53.

Accepted 27 January 1992 